\title{
A Study to Establish Correlation Between Intercolumnar Cracks in Slabs and Off-Center Defects in Hot-Rolled Products
}

\author{
Diptak Bhattacharya $\cdot$ T. K. Roy $\cdot$ Vinay V. Mahashabde
}

Submitted: 17 September 2015/in revised form: 11 November 2015/Published online: 28 December 2015

(C) ASM International 2015

\begin{abstract}
Delamination and cracking related to segregations are mostly observed at the centerline of hot-rolled products. The delamination is related to heavy concentration of manganese sulfide inclusions originating from centerline segregation in slabs. In multiple cases, similar delamination or cracking is observed at locations away from the mid thickness plane of hot-rolled products during forming operations at customer end. This leads to rejection of materials. Metallographic investigation reveals segregation line with plenty of manganese sulfide stringers at the off-center location similar to observations in cases of centerline defects. Centerline segregation is a well-understood phenomenon, but the presence of off-center segregation line in hot-rolled products has not been systematically studied before. Several literatures report intercolumnar cracks in slabs to be filled with segregations. Also, they occur away from the centerline of continuously cast slabs. A laboratory-based experimental study was conducted using a slab suspected by S-printing to contain
\end{abstract}

D. Bhattacharya $(\bowtie)$

Product Technology Flat Products, India, Tata Steel Ltd., Stage

Lab, LD3\&TSCR, TATA Steel Ltd., Jamshedpur 831005,

Jharkhand, India

e-mail: diptak.bhattacharya@tatasteel.com

T. K. Roy

Product Technology Flat Products, India, Tata Steel Ltd., LD2\&SC, TATA Steel Ltd., Jamshedpur 831005, Jharkhand, India

e-mail: tkr@tatasteel.com

\section{V. Mahashabde}

Product Technology Flat Products, India, Tata Steel Ltd., Office of Chief Technology Officer (Flat Products), TATA Steel Ltd., Jamshedpur 831005, Jharkhand, India

e-mail:vvmaha@tatasteel.com intercolumnar cracks. The aim of this study was to evaluate the effect of intercolumnar cracks on internal quality of rolled products. This paper reports the finding of this study that established a strong correlation between intercolumnar cracks in slabs and off-center cracking in hot-rolled products.

Keywords Intercolumnar cracks - Macroetching · Sulfur print $\cdot$ Segregation

\section{Introduction}

Internal quality of hot-rolled sheets or plates is crucial for the sound performance of products during their forming and final application. There have been several instances when delamination or cracks are reported at the mid thickness location of hot-rolled products during forming stage as shown in Fig. 1. Metallographic investigations in most cases reveal a segregation band of manganese sulfide stringers along the centerline of rolled products indicating the defect to have originated from centerline segregation in slab.

During cold-forming operations, some customers of hotrolled products reported similar delamination or cracking at locations away from the centerline (henceforth, denoted as off-center) as shown in Fig. 2a, b, respectively. Metallographic investigations indicate a segregation line along the off-center crack location similar to that observed to occur on account of centerline segregation in slabs. This may be noted from Fig. 3. Optical microscopy reveals elongated stringers of manganese sulfide in the off-center segregation band as shown in Fig. 4. This clearly suggests that the segregation at the off-center location of the rolled product leads to delamination or cracks during forming operations. 


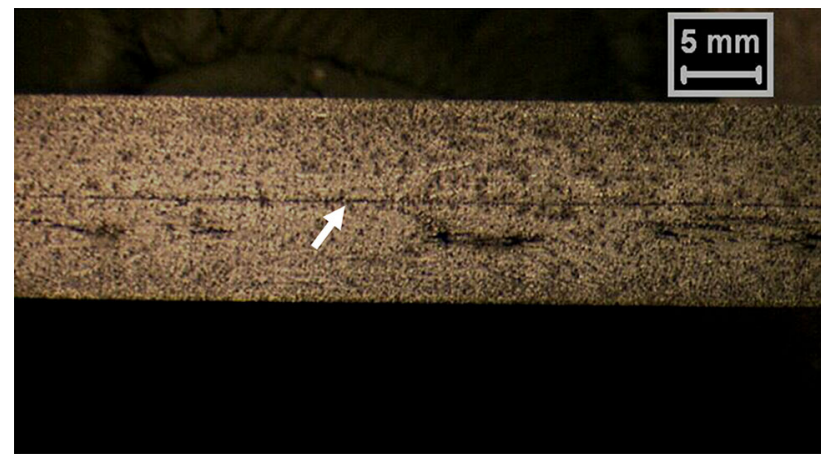

Fig. 1 Crack-like defect at centerline of hot-rolled product arising due to centerline segregation
The off-center segregation lines may be observed above or below the mid thickness plane of the hot-rolled products or sometimes in both directions, as shown in Fig. 5. Sometimes they are present in addition to centerline segregation. The presence of segregation line at the center of hot-rolled products is a well-studied phenomenon but similar segregation line at off-center locations is not well understood. However, the presence of segregations suggests that the delamination at off-center locations is related to some pre-existing internal defects in the continuously cast slab.

The mushy zone is the region of a continuously cast strand where the solid and liquid coexist as a mixture. In

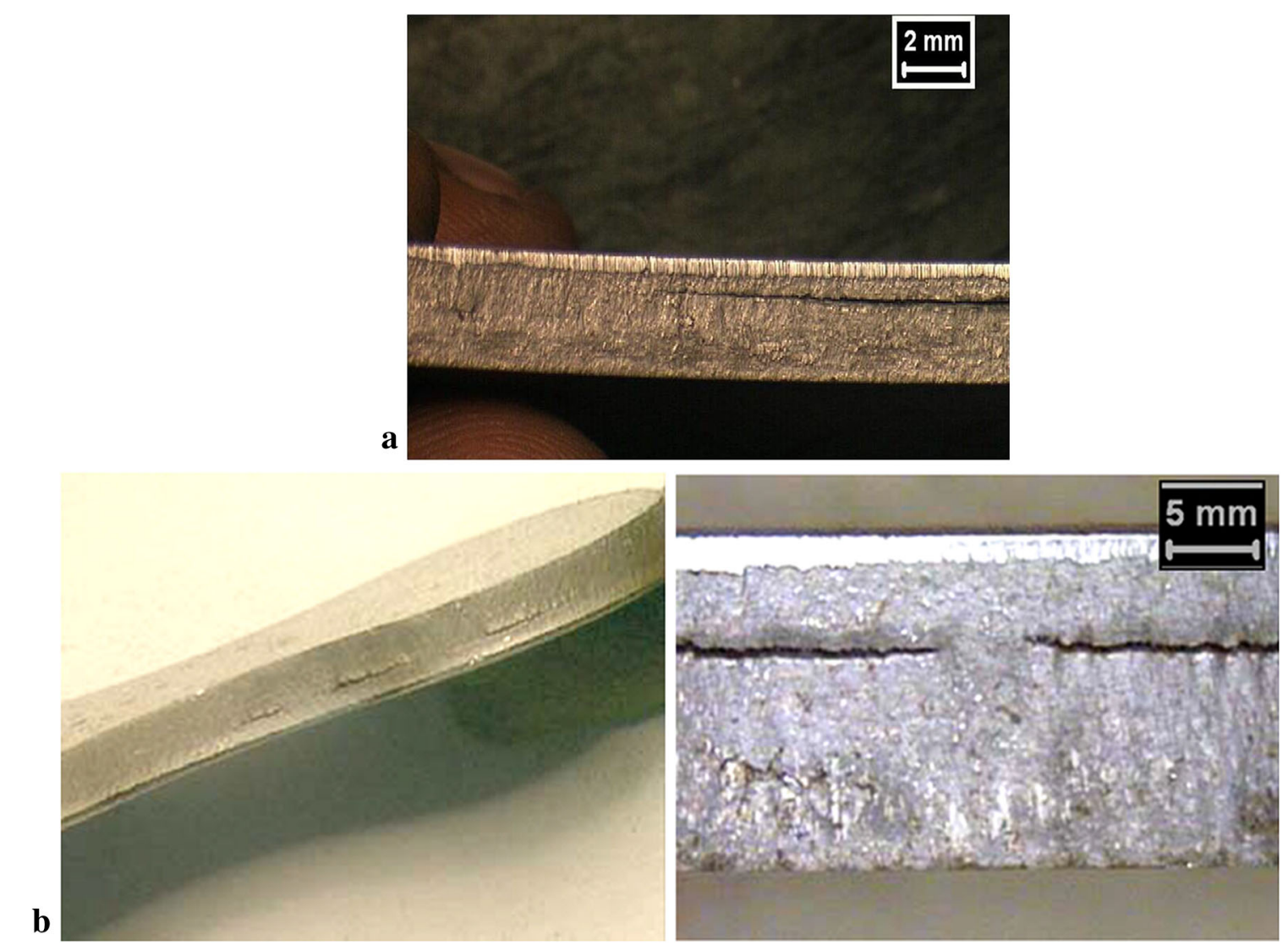

Fig. 2 Crack-like defect at off-center location of hot-rolled plates observed after forming

Fig. 3 Photograph of transverse section of rolled product revealing segregation band along the crack line at offcenter location after macroetching (50 vol\% HCL)

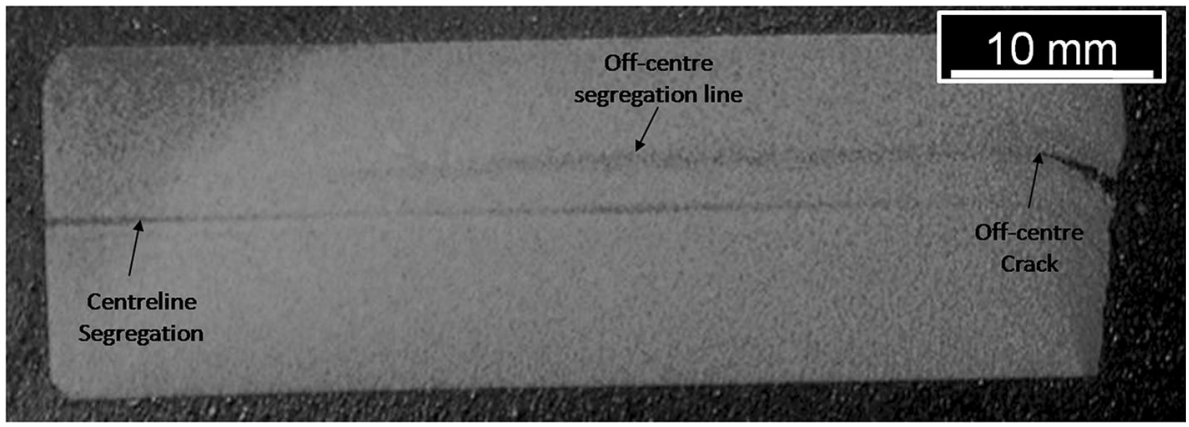


Fig. 4 Optical micrographs indicating the presence of manganese sulfide stringers at the off-center crack locations

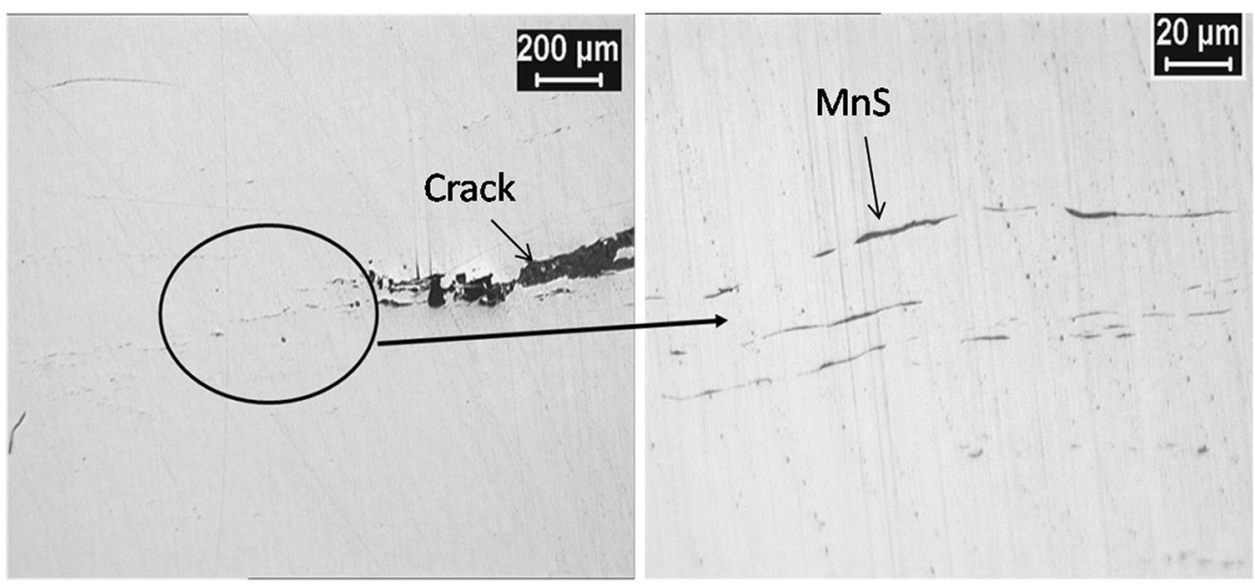

$2 \mathrm{~mm}$ $\longmapsto$

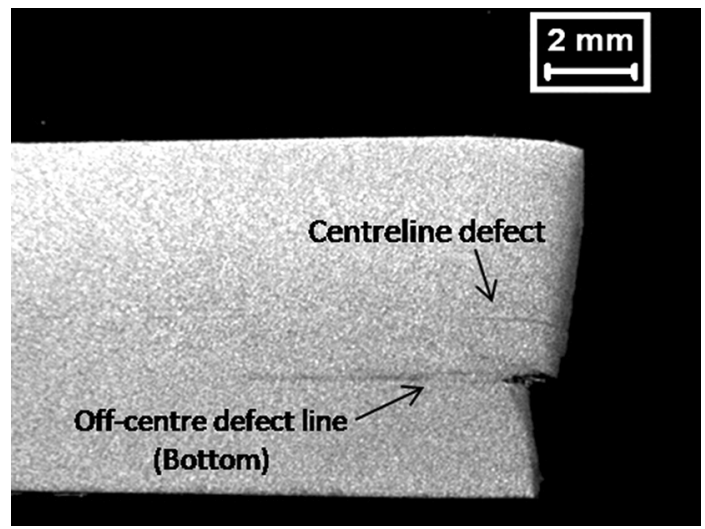

Fig. 5 Transverse section of macroetched hot-rolled products showing segregation band at centerline and (A) off-center location in one direction (B) off-center location in both directions about the mid thickness plane

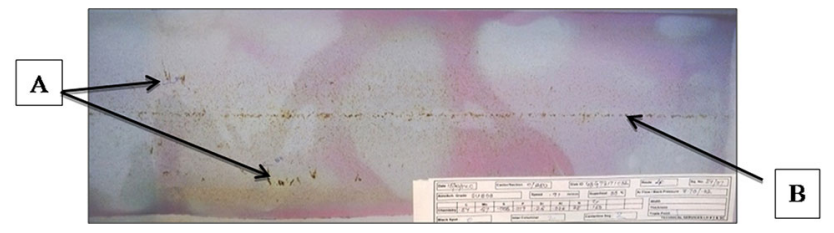

Fig. 6 Sulfur print plate of transverse section of a cast slab showing (A) intercolumnar cracks and (B) centerline segregation

the Brittle Temperature Range (Zero Strength Temperature to Zero Ductile Temperature), this zone is characterized by extremely low-critical strain to fracture [1]. When the combined strain arising on the solidifying front due to strand bulging, misaligned segment rolls, or uneven solidification exceeds a critical strain, there are chances of forming intercolumnar cracks [2-5]. Since the surrounding of the cracks contains solute-rich interdendritic liquid, there are possibilities of the cracks to get filled with the segregated liquid. However, at some locations having heavy interdendritic bonding, the flow of fluid may be blocked and the cracks may remain open and unfilled [1].
The susceptibility toward forming intercolumnar cracks during solidification depends majorly on the extent of Brittle Temperature Range. Segregating elements like sulfur and phosphorus lower solidification temperature of steel below its equilibrium solidus, thereby enhancing this range [1]. In this perspective, high-carbon steels are more prone to cracking as compared to low-carbon steels because of their larger solidification range $\left(T_{\text {solidus }}-T_{\text {liq- }}\right.$ uidus). Also segregation tendencies of sulfur and phosphorus are higher when solidification occurs in austenitic mode as in case of high-carbon steels [6].

Sulfur printing (S-print) of transverse section of cast slab is a common technique to evaluate its internal quality. This technique is generally used to judge the severity of centerline segregation and intercolumnar cracks in slabs. Figure 6 shows the photograph of a typical sulfur print plate of a slab having centerline segregation and intercolumnar cracks. Intercolumnar cracks are observed at the off-center locations of the slabs. Various literatures also report possibilities of them to be filled with solute-enriched segregated liquid. Therefore, question arises whether these cracks are related to the off-center segregation line in rolled products.

Several authors have studied the origin and formation of internal defects like centerline segregation and intercolumnar cracks in continuously cast slabs. Effect of centerline segregation in cast slabs on the internal quality of the hot-rolled products is also well known $[6,7]$. However, the effect of the intercolumnar cracks in slabs on the internal quality of hot-rolled product is an area which has not been significantly explored before. There is a general conception that the internal cracks get welded during hotrolling operation. This may be true for crack portions remaining open in slab and free from segregations. However, whether the same is applicable to crack portions filled with segregated liquid is a question. Through systematic laboratory experimentations, the present work is aimed to establish a strong correlation between intercolumnar cracks 
Table 1 Technical specification of CC\#3 of LD2\&SC shop of TATA Steel Jamshedpur works

\begin{tabular}{ll}
\hline & Caster specifications \\
\hline Caster type & Curved (bow type) \\
Mold type & Curved \\
Ladle capacity & $165 \mathrm{~T}$ \\
Tundish design & Step type tundish \\
Tundish capacity & $35 \mathrm{~T}$ \\
SEN design & $15^{\circ}$ double port (Slit SEN) \\
Mold length & $900 \mathrm{~mm}$ \\
Number of segments & 15 \\
Bending radius & $10 \mathrm{~m}$ \\
Bending/unbending & Multi-point \\
Metallurgical length & $30.5 \mathrm{~m}$ \\
\hline
\end{tabular}

Table 2 Continuous casting parameters of the slab under study

\begin{tabular}{ll}
\hline \multicolumn{2}{c}{ Casting parameters } \\
\hline Slab dimension & $218 \mathrm{~mm} \times 1250 \mathrm{~mm}$ \\
Casting speed & $0.9 \mathrm{~m} / \mathrm{min}$ \\
Superheat & $23^{\circ} \mathrm{C}$ \\
Tundish weight & $32 \mathrm{~T}$ \\
Primary cooling water (broad side) & $4000 \mathrm{~L} / \mathrm{min}$ \\
Primary cooling water (narrow side) & $500 \mathrm{~L} / \mathrm{min}$ \\
Secondary cooling water & $1500 \mathrm{~m}^{3} / \mathrm{h}$ \\
\hline
\end{tabular}

in cast slab and off-center defects in hot-rolled plates or strips.

\section{Experimental Procedure}

\section{Sample Collection}

Various grades of steel produced in TATA Steel, Jamshedpur require sound internal quality for precision applications like automobile shockers, chain links, long members, etc. Such grades have carbon content ranging from $0.07 \mathrm{wt} . \% \mathrm{C}$ to $0.55 \mathrm{wt} . \% \mathrm{C}$. Complaints regarding off-center cracking were reported in most of these grades, and the rejection rates were around $8 \%$. One among such grades having $0.55 \mathrm{wt} . \%$ carbon was randomly taken up for the study.

A slab having composition of Fe-0.55C-0.75Mn-0.007S0.015P-0.21Si was selected, whose S-print plate indicated the presence of intercolumnar cracks. The slab was cast in CC\#3 of LD2\&SC shop in TATA Steel, Jamshedpur works. The technical specification of this continuous caster is shown in Table 1, and the continuous casting parameters of the slab under study are listed in Table 2. According to

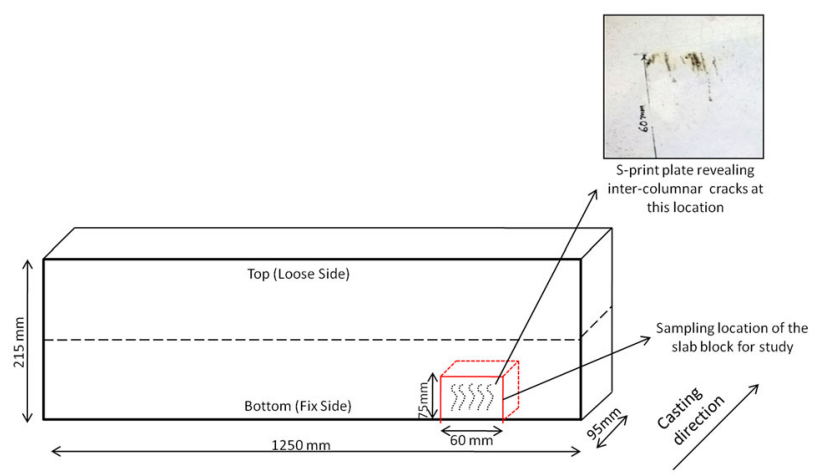

Fig. 7 Schematic illustration of sampling location of slab block from S-print slab sample

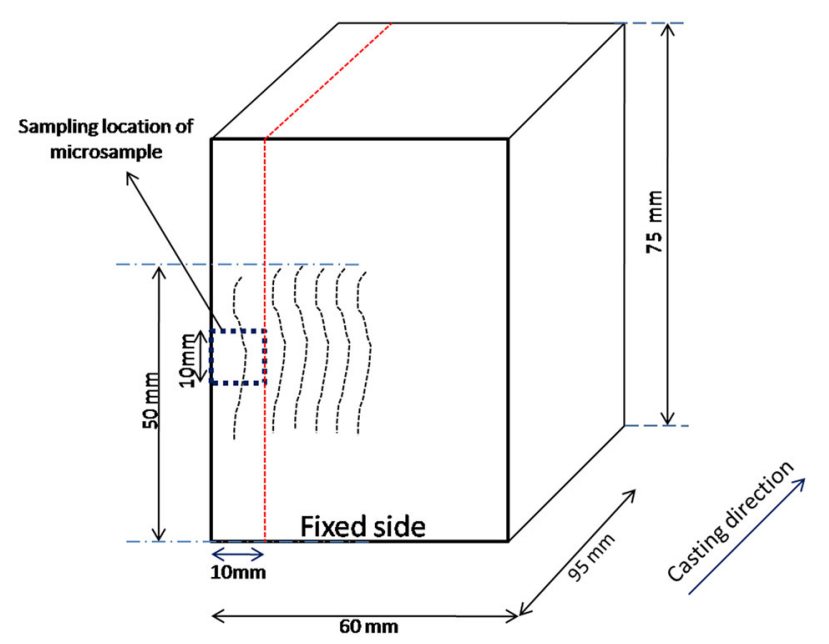

Fig. 8 Sampling location of microsample from suspected crack portion in the slab block

S-print plate, the cracks were present below the centerline of the slab and extended between 30 and $50 \mathrm{~mm}$ from the bottom surface (fixed side). The corresponding S-print slab sample, separated off line from the tail end of the original slab, was considered for our study to assess the impact of intercolumnar cracks on rolled product quality. Due to the absence of laboratory facilities to roll slab samples of full thickness, a small block $(60 \mathrm{~mm} \times 95 \mathrm{~mm} \times 75 \mathrm{~mm})$ was separated from the S-print sample $(1250 \mathrm{~mm} \times 95 \mathrm{~mm} \times$ $215 \mathrm{~mm}$ ) at the suspected location of intercolumnar cracks. The sampling location of the slab block from the S-print sample is schematically illustrated in Fig. 7. During sample retrieval, precautions were taken to cause no damage to the intercolumnar crack portion. Additionally, sampling was such that centerline portion of the slab was avoided. This would ensure that the slab block contained no defect other than the intercolumnar cracks and an unbiased analysis of their impact on the rolled product quality could be carried out. 


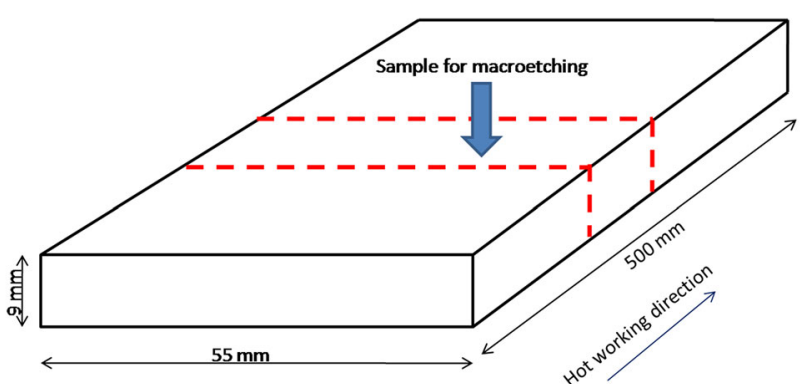

Fig. 9 Sampling location from hot worked plate of 9-mm thickness

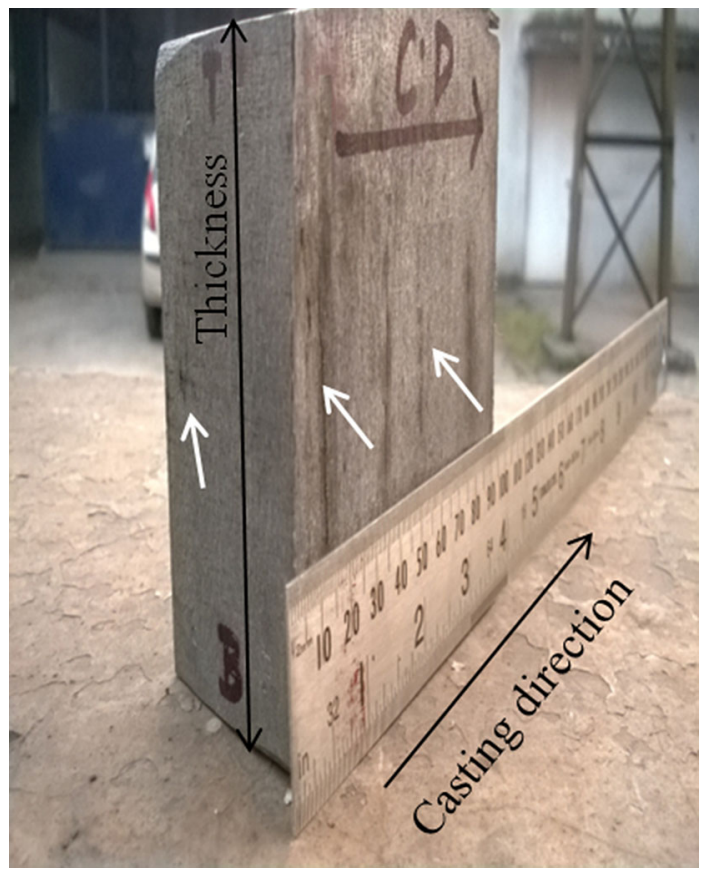

Fig. 10 Macroetched slab block revealing intercolumnar cracks. (actual photograph)

\section{Microscopic Analysis of the Intercolumnar Crack Portion} in the Slab

A microsample of dimension $10 \mathrm{~mm} \times 10 \mathrm{~mm} \times 10 \mathrm{~mm}$ was separated from the suspected location of intercolumnar cracks in the slab block. The schematic illustration of its sampling location is represented in Fig. 8. The collected microsample was hot mounted, polished, and observed under optical microscope (Lieca, model: DMRX, Germany) in unetched condition. Following this, studies were made under FE-SEM (Model: Ziess, Vorpommern, Germany) with EDAX and X-ray mapping attachments.

\section{Macroetching}

The transverse and longitudinal faces of the slab block $(50 \mathrm{~mm} \times 95 \mathrm{~mm} \times 75 \mathrm{~mm})$ were prepared using Vertical

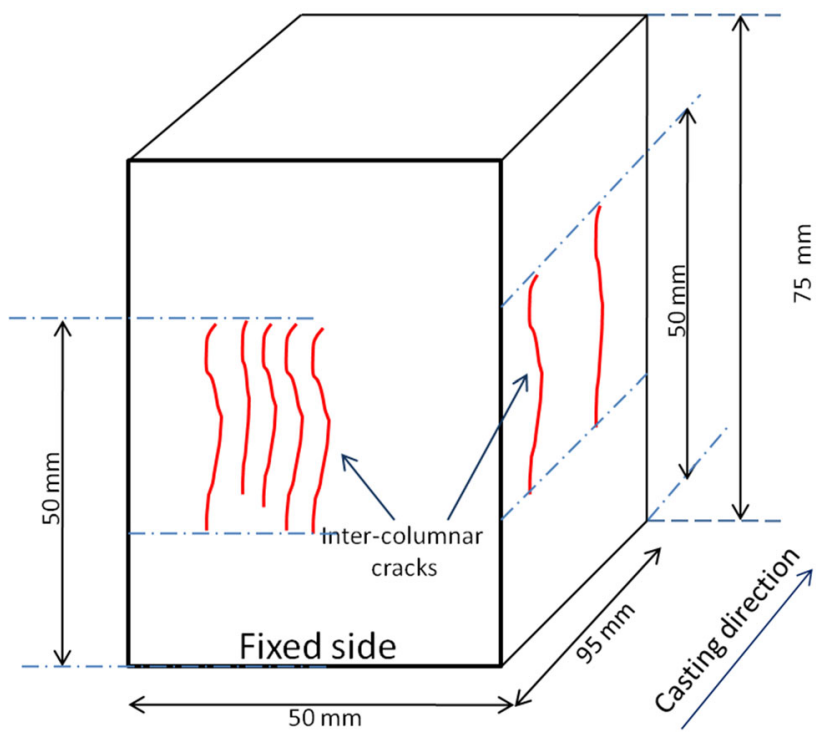

Fig. 11 Schematic diagram of macroetched slab block

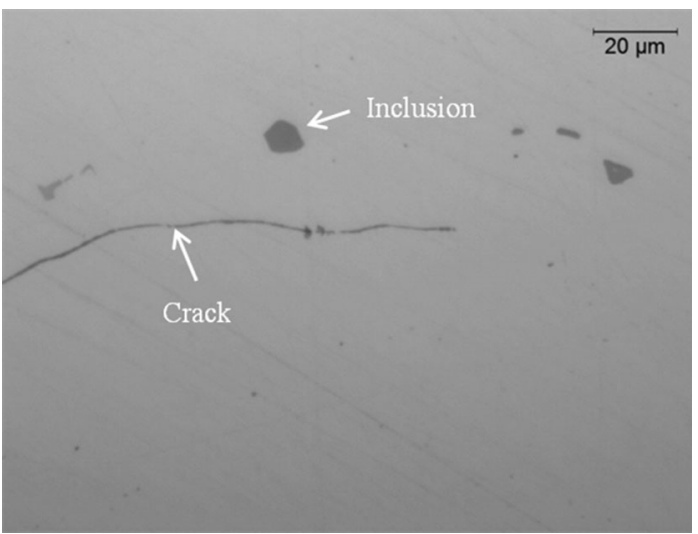

Fig. 12 Unetched slab sample showing the presence of globular inclusions near the crack $(\times 500$ magnification)

milling machine (Model: VF-1). The prepared sample was then macroetched according to ASTM E340-13 standard. The block was completely immersed for $2 \mathrm{~h}$ in a freshly prepared $\mathrm{HCl}$ solution (1:1 by volume) maintained at a temperature of $70{ }^{\circ} \mathrm{C}$. After proper cleaning and drying, the block was examined for the presence of intercolumnar cracks.

Hot Working of the Slab Sample to a Plate of 9-mm Thickness

The slab block containing the intercolumnar cracks was reheated to a temperature of $1220{ }^{\circ} \mathrm{C}$ in electric trolley furnace and soaked for $1 \mathrm{~h}$. The sample was then hot worked using laboratory facility to a plate of 9-mm thickness, through multiple passes. 
Fig. 13 X-ray mapping

revealing manganese and sulfur

in globular inclusion
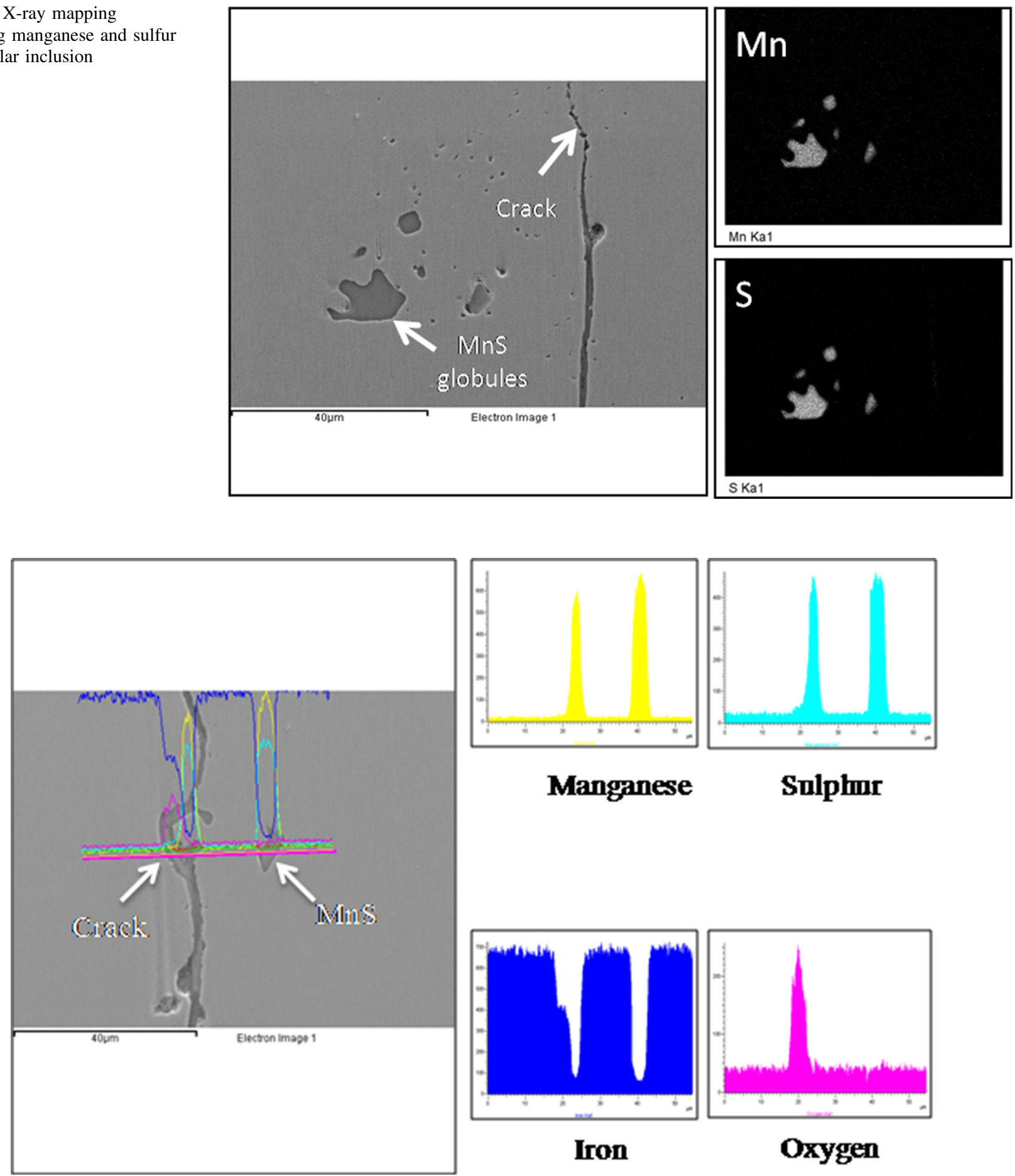

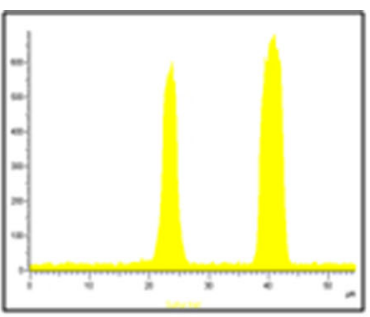

Manganese

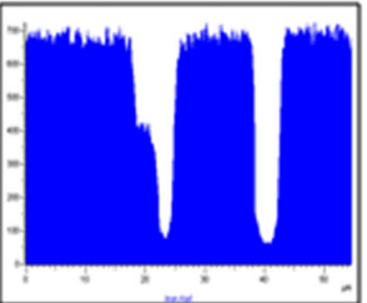

Iron

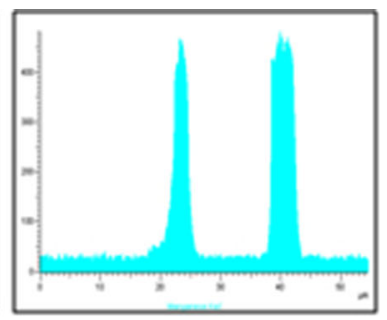

Salphmr

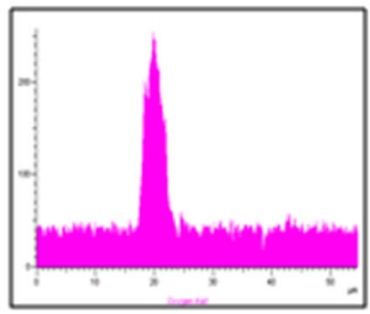

Oxygen

Fig. 14 EDS line scan across the crack indicating MnS both inside as well as in the vicinity of the intercolumnar crack

Macroetching of the Transverse Section of the Hot Worked Plate

In order to examine its internal quality, a sample was retrieved from the hot worked plate as indicated schematically in Fig. 9 using hydraulic shear machine (Model: HVR 2020). The transverse face of the cut out sample was prepared, macroetched, and investigated for the presence of any defects.

Microscopic Analysis of the Hot Worked Plate

A microsample was separated from the defect portion of the macroetched hot worked plate sample. In order to 


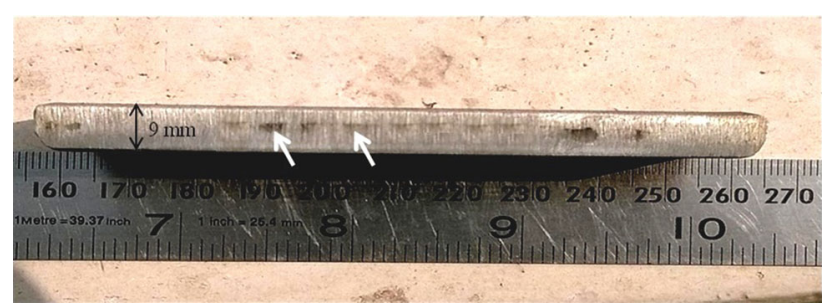

Fig. 15 Defects in hot worked plate sample arising from intercolumnar cracks in the slab sample

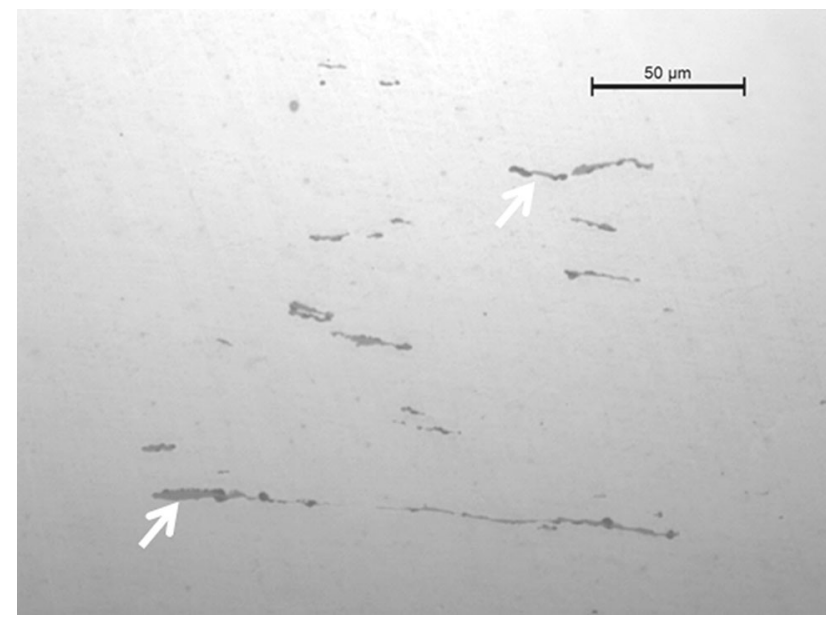

Fig. 16 Unetched hot worked plate sample showing MnS stringers at the defect location $(\times 500$ magnification $)$

identify the exact nature of the defect, optical microscopic investigation was carried out on the polished microsample in unetched and etched ( $2 \mathrm{wt} . \%$ nital) condition. The sample was then subjected to SEM-EDX analysis using FE-SEM (Model: Ziess, Vorpommern, Germany) with EDAX and X-ray mapping attachments.

\section{Results and Discussions}

\section{Investigation of Intercolumnar Crack in Slab}

Macroetching of the slab block revealed the internal cracks from the original slab. These cracks are observed perpendicular to the casting direction and at several locations in the transverse faces of the slab block as shown in Fig. 10. All the cracks are at same distance with respect to the bottom surface of the slab as noted from the schematic diagram of the macroetched slab block in Fig. 11. Since these cracks are generated at the solidification front, the distance (' $s$ ') of the cracks from the adjacent slab surface may be employed in solidification equation, $d=v(s / k)^{2}$ (where $s$-shell thickness $(\mathrm{mm}) ; k$-machine constant $(\mathrm{mm} /$ $\left.\min ^{2}\right) ; v$-casting speed $(\mathrm{mm} / \mathrm{m})$; and $d$-distance from meniscus (mm)) to roughly estimate the location in the caster where the cracks would have formed. For the slab under study, this distance (' $d$ ') is obtained to be $6640 \mathrm{~mm}$ (putting $s=50 \mathrm{~mm}, \quad v=1100 \mathrm{~mm} / \mathrm{min}, \quad$ and $k=20.35 \mathrm{~mm} / \mathrm{m}$ ), which corresponds to 9 th segment of the caster which was observed with misaligned guide rolls. Misaligned rolls may result in deformation of the solid shell due to bulging of strand between support rolls, imposing strain on the solidification front leading to internal cracks [2]. It may therefore be understood that even the interior of the slab block would contain similar cracks along the plane of cracks revealed on the surface of the slab block.

The unetched microsample as observed under optical microscope is shown in Fig. 12. It reveals the presence of globular inclusions in the vicinity of an intercolumnar crack. X-ray elemental mapping identifies the globular inclusions to be of manganese sulfide origin as shown in Fig. 13. SEM-EDS line scan analysis was carried out across the crack at multiple locations and the manganese sulfide-type inclusions are indicated inside the crack as well. One such location may be noted from Fig. 14. It may be understood that as intercolumnar cracks formed in the mushy zone during casting, it world have created a suction of solute-rich liquid from the neighboring interdendritic spaces to fill the cracks. This resulted in accumulation of solute elements like sulfur at certain locations inside and in the surroundings of the crack. Consequently, it led to the formation of inclusions observed in association with the intercolumnar cracks.

\section{Investigation of Defect in the Hot Worked Plate}

On macroetching, the transverse face of the hot worked plate sample reveals a segregation band (defect line) as shown in Fig. 15. This resembles with observation of centerline segregation in macroetched hot-rolled plate samples. Also, the segregation band is similar to that found associated with off-center crack locations in defect component as shown in Figs. 3 and 4. Optical microscopy in unetched condition reveals plenty of fine stringers at the segregation band location as shown in Fig. 16. Using EDS point analysis, the stringers are confirmed to be of manganese sulfide type as represented in Fig. 17.

The manganese sulfide stringers in the rolled plate originate from the globular sulfide inclusions observed in association with the intercolumnar crack in the slab. The presence of stringers at the defect location in plate suggests that the segregations inside and around the intercolumnar cracks do not disappear on rolling. Rather, they accumulate along some plane in the rolled product, forming a segregation band. The location of this segregation band with respect to the thickness direction of the rolled plate is 


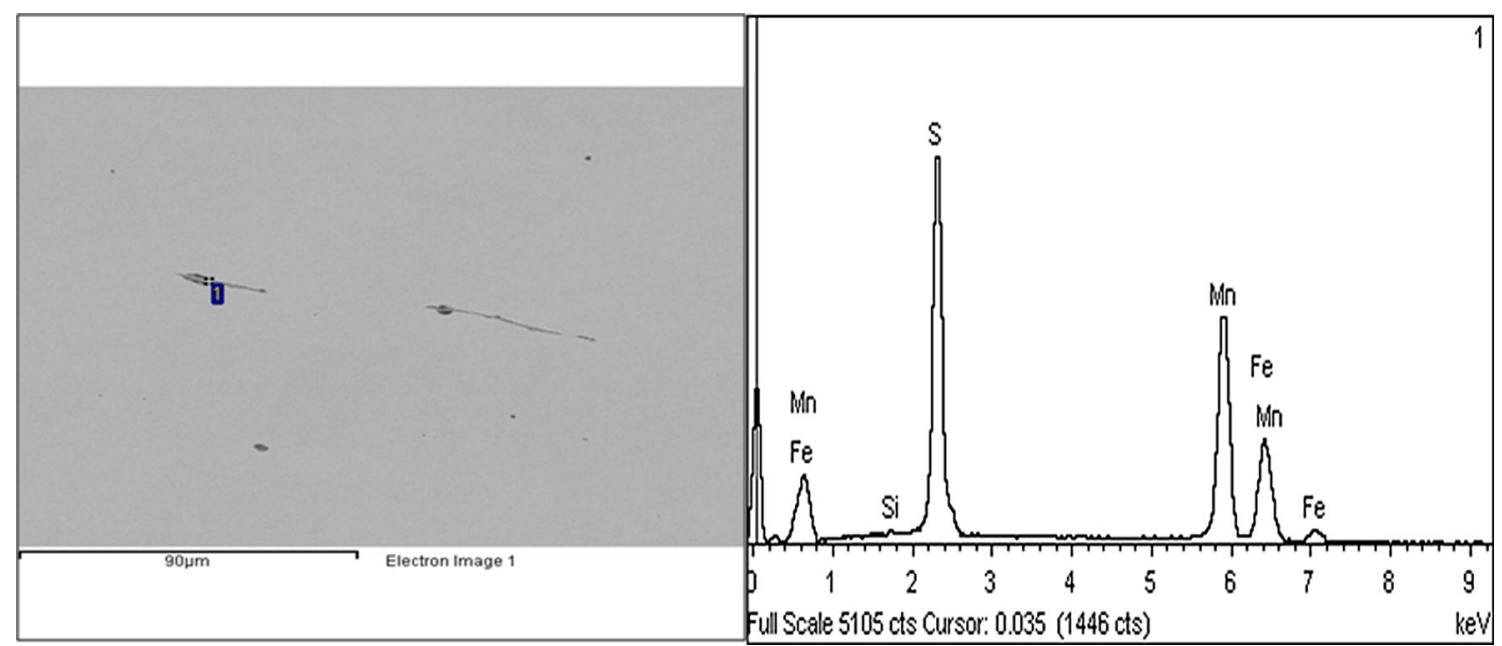

Fig. 17 EDS analysis confirming the presence of MnS stringers at defect portion in hot worked plate

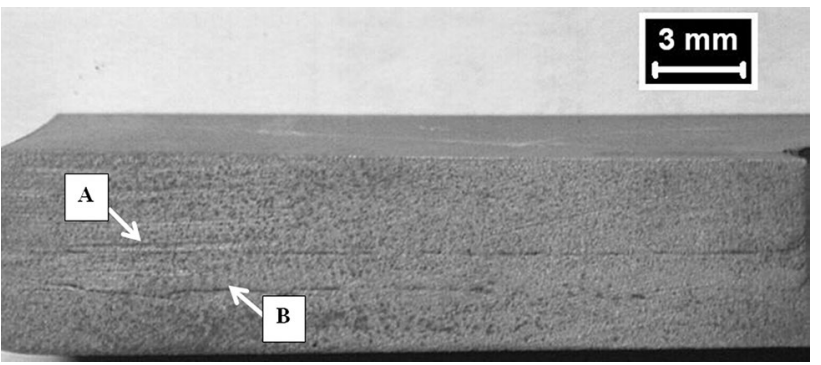

Fig. 18 Transverse section of rolled plate showing both centerline defect band (A) and off-center defect band (B)

dependent on the location of the intercolumnar cracks with respect to the transverse direction of the slab. During coldforming operations, delamination or cracking may occur along this plane containing heavy concentration of segregates and inclusions.

A slab having both centerline segregation and intercolumnar cracks is suspected to create multiple defect bands in the transverse section of the hot-rolled products as shown in Fig. 18. In that case, the segregation band developed due to intercolumnar cracks would be away from the centerline of the hot-rolled product. As there is no facility to experimentally roll full thickness slab samples, investigation of hot-rolled plate samples collected from a rolling mill may validate above hypothesis.

Another slab block was sampled that did not contain any intercolumnar cracks. This slab block was then rolled in a similar procedure as the block containing intercolumnar cracks. The transverse section of the corresponding hot worked plate was macroetched and no segregation band (defect line) was revealed, as shown in Fig. 19. This indicates that slab blocks that do not contain intercolumnar defects do not form the type of off-center cracking observed above and supports the effect of intercolumnar

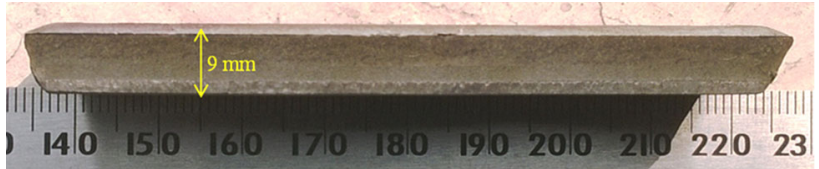

Fig. 19 Defect-free hot worked plate obtained from slab sample without intercolumnar crack

cracks on the formation of defect lines (cracking) in hotrolled products.

\section{Recommended Actions to Reduce Off-Center Cracking}

From this experimental study, a strong correlation is seen to exist between the intercolumnar crack in slabs and offcenter defect in hot-rolled strips. Thus, any countermeasure taken to reduce occurrence of intercolumnar cracks is likely to reduce generation of off-center defects in the rolled products.

Sulfur content of steel plays a crucial role in the generation of intercolumnar cracks. It is recommended to lower sulfur levels in steel to avoid intercolumnar cracks in slabs and thereby off-center defects in rolled products. In TATA Steel, the sulfur content is restricted to $0.005 \%$ for all grades facing off-center cracking at customer end during forming applications. Secondly, casting parameters like superheat and casting speed are similarly optimized to reduce crack occurrences in slabs. Casting speed is restricted to $1 \mathrm{~m} / \mathrm{min}$ and superheat is maintained in the range of $15-25^{\circ} \mathrm{C}$. Thirdly, misaligned segment rolls in caster increase propensity for developing intercolumnar cracks. Therefore, it is recommended to cast the critical grades only after roll gaps and alignments in the caster segments are properly checked. Also, for these grades, no coils are sent to customers if its corresponding slab revealed intercolumnar cracks during S-printing. 
Intercolumnar cracks are not specific to any particular grade. Therefore, chances of observing off-center defects span all grades. Similarly, recommendations for preventing off-center cracking apply to all grades. High-carbon grades are more prone to cracking and therefore forming offcenter defects because of reasons already discussed. Implementing the aforesaid actions has reduced rejection rates at customer end from $8 \%$ in FY' 13 to $0.3 \%$ in FY' 15 .

\section{Conclusions}

Following conclusions may be drawn from the present study:

(1) Intercolumnar cracks lead to off-center segregation bands in rolled products which may result in delamination or cracking during forming operations.

(2) Reduction of the occurrences of intercolumnar cracks reduces chances of off-center cracking.

(3) The occurrence of off-center cracking can be reduced by (a) reducing the sulfur content of the steel (b) properly checking the roller gaps and alignment of caster segments prior casting complaint facing grades, and (c) ensuring that coils rolled from slabs containing intercolumnar cracks do not reach customers.
Acknowledgments The authors wish to thank colleagues from Tata Steel Ltd for their support and encouragement in completion of the work. Help received from National Metallurgical Laboratory, Jamshedpur for carrying out experiments using their laboratory facilities is also appreciated.

\section{References}

1. B. Santillana, R. Boom, D. Eskin, H. Mizukami, M. Hanao, M. Kawamoto, High-temperature mechanical behavior and fracture analysis of a low-carbon steel related to cracking. Metall. Mater. Trans. A 43A, 5048-5057 (2012)

2. Z. Han, K. Cai, B. Liu, Prediction and analysis on formation of internal cracks in continuously cast slabs through mathematical models. ISIJ Int. 41, 1473-1480 (2001)

3. A. Yamanaka, K. Nakajima, K. Okamura, Critical strain for internal crack formation in continuous casting. Ironmak. Steelmak. 22(6), 508-512 (1995)

4. T. Matsumiya, M. Ito, H. Kajioka, S. Yamaguchi, Y. Nakamura, An evaluation of critical strain for internal crack formation in continuously cast slabs. Trans. Iron Steel Inst. Jpn. 26, 540-546 (1986)

5. K. Wunnenberg, R. Flender, Investigation of internal crack formation, using a hot model. Ironmak Steelmak 12(n1), 22-29 (1985)

6. A. Ghosh, Segregation in cast products. Sadhana 26(Parts 1 \& 2), 5-24 (2001)

7. F. Mayer, M. Wu, A. Ludwig, On the formation of centreline segregation in continuous slab casting of steel due to bulging and/ or feeding. Steel Res. Int. 81(8), 660-667 (2010) 